\title{
Stress and emotions at work: An adventure tourism guide's experiences
}

\author{
Susan Houge Mackenzie ${ }^{\mathrm{a}, *}$, John H. Kerr ${ }^{\mathrm{b}}$ \\ a Dept. of Movement Sciences, PO Box 442401, College of Education, University of Idaho, Moscow, ID 83844-2401, USA \\ ${ }^{\mathrm{b}}$ School of Kinesiology, University of British Columbia, Vancouver, BC, Canada
}

\section{H I G H L I G H T S}

- Applies psychological theory (reversal theory) to understand adventure guiding experiences.

- Unique autoethnographical account of adventure tourism guiding experiences.

- Identifies sources of stress and emotions experienced in the employer-guide relationship.

- Recommends how to reduce stress for adventure guides.

- Discusses future directions regarding psychological research in tourism.

\begin{abstract}
A B S T R A C T
Little research has identified issues faced by tour guiding professionals and investigations of tour guide experiences have been neglected in favour of tourist experience and behaviour studies. Even less research has focused on adventure guiding experiences and potential sources of stress and emotions in this context. Studies that have investigated adventure guide experiences generally focused on guide-client interactions and sociological accounts of these experiences. Due to these gaps in the literature, and the recognised potential of psychological theories to enhance studies of stress and emotions in tourism settings, this study explored stress and emotions resulting from employer-guide interactions in an adventure tourism context from a psychological perspective. Longitudinal autoethnographical data was recorded during a river guiding season in South America. A reversal theory framework guided data analyses of key motivational states, sources of stress, and resulting emotions. Analyses identified potential transactional sources of stress and negative emotions for adventure tourism guides, and motivational states associated with stress and emotional outcomes in the employer-guide relationship. Results are discussed in relation to psychological theory and stress and coping research. Recommendations for practice, that could alleviate stressful experiences between employers and guides, are also discussed.
\end{abstract}

\section{Introduction}

\subsection{Significance of the study}

Tourism research has successfully employed psychological models to examine tourists' experiences (e.g., Pearce, 1987, 1991, 1996, 2011). However, the literature has often neglected the study of guide experiences by focussing primarily on tourist experiences and behaviours. Few studies of issues faced by tour guiding professionals have been reported in the English-based literature. Research that has begun to identify a range of issues confronting tour guides (e.g., Ap \& Wong, 2001; Mak, Wong, \& Chang, 2011) has

\footnotetext{
* Corresponding author. Tel.: +1 208885 2164; fax: +1 2088855929.

E-mail addresses: smackenzie@uidaho.edu, shouge2000@yahoo.com (S. Houge Mackenzie).
}

generally neglected to examine the psychological aspects of encountering these issues, such as stress and emotional responses.

These observations also apply to the sub-field of adventure tourism. Although adventure tourism is a fast-growing industry (Xola Consulting, 2010), research has focused on participants' psychological experiences of adventure activities (e.g., Houge Mackenzie, Hodge, \& Boyes, 2011; Sibthorp, Paisley, \& Gookin, 2007), rather than psychological aspects of working in adventure tourism. Investigations of adventure tourism experiences have generally concentrated on market segmentation approaches, tourist participation motives, consumptive emotions, and the impact of guide-to-client interactions on tourist satisfaction over brief time spans (e.g., Arnould \& Price, 1993; Huang, Hsu, \& Chan, 2010; Mak et al., 2011; Pomfret, 2011; Van Dijk, Smith, \& Cooper, 2011; Weber, 2008). A limited number of sociological studies have identified emotional and performative labour issues encountered 
by adventure guides in guide-to-client interactions (e.g., Holyfield \& Jonas, 2003; Sharpe, 2005). These studies indicate that, similar to many service industry workers, adventure guides engage in emotional and performative labour due to expectations to perform and display emotions consistent with organisational and social expectations, even if they conflict with internal feelings.

This body of literature has predominantly represented 'external' perspectives on tourist or guide experiences in either Englishspeaking or Asian countries. Notable exceptions include sociological studies conducted by mountaineering guides that present an 'insiders' perspective on mountaineering adventure tourism (Beedie, 2003; Pomfret, 2006). While these studies (e.g., Beedie, 2003; Holyfield \& Jonas, 2003; Pomfret, 2006; Sharpe, 2005) have presented sociological accounts of adventure guiding and identified emotional labour associated with guide-to-client interactions, psychological investigations of stress and emotions in adventure guiding resulting from other interpersonal interactions (e.g., employer-guide; guide-to-guide) are lacking. Understanding the emotional experience of adventure guiding over time and potential sources of stress is important not only for guide well-being, but also to help reduce issues such as burnout, turnover, and poor service quality. The current study begins to address gaps in the tourism literature by providing a longitudinal 'insider' account of adventure tourism guiding in a South American country that uses established psychological theory to identify sources of stress and emotions experienced in this context.

\subsection{Tourism work, psychological stress, and emotions}

Although tourism is often portrayed as a hedonistic endeavour (e.g., Goossens, 2000), research indicates that travel is stressful and can be associated with negative health and well-being outcomes (e.g., Furnham, 1984; Pearce, 1981; Pearce \& Stringer, 1991; Prokop, 1970; Spradley \& Phillips, 1972). Studies of tourists' experiential patterns and consumptive emotions demonstrate that emotional fluctuations occur over time in relation to daily activities and motivations (e.g., Coghlan \& Pearce, 2009). Although the consumptive tourism experience (leisure) is contextually distinct from the tourism guiding experience (work), adventure guides may share some of the stressors experienced by tourists albeit over longer time frames.

Due to the travel often involved in this profession, stressors may include differences in culture, language, food, hygiene, living quarters, amenities, and transportation options, as well as differences in more subtle aspects of everyday life, such as "humor, intimacy, privacy, etiquette, and formality" (Berno \& Ward, 2005, p. 595). While a guide will no doubt become more accustomed to dealing with these stressors than a tourist, little research has evaluated key stressors in the adventure guide experience over time.

Law, Pearce, and Woods (1995) highlighted the need to apply stress and coping research to tourism and hospitality employees, and identified clear sources of stress and coping strategies of Australian attractions staff. Sources of stress included poor communication from management; lack of recognition/incentives; job insecurity; and job demands such as dealing with difficult clients, insufficient staff, boredom, and repetition. Hospitality and attractions tourism staff experience a range of stressors (e.g., Ross, 1993), many of which are related to management practices and interpersonal interactions. Studies of outdoor field instructors in wilderness settings support the notion that adventure guides may experience a range of work-related stressors. The intensive lifestyle required of wilderness field workers can negatively affect interpersonal relationships (e.g., Bunce, 1998; Gass, 1993) and stressors such as emotional challenges related to client interactions and high reported levels work-related anxiety contribute to burnout and turnover (Marchland, Russell, \& Cross, 2009).

Emotional, aesthetic, and performative labour literature has also identified stressors that occur as a result of social expectations regarding appropriate emotional expression, aesthetic presentation, or performative aspects of work (e.g., Fine \& Speer, 1985; Hochschild, 1983; Witz, Warhurst, \& Nickson, 2003). Beedie (2003) highlighted the role of mountaineer guides as 'choreographers' of experiences and many tour leaders in Wong and Wang's (2009) study considered themselves to be 'aesthetic laborers' acting as the face of their company. Wong and Wang (2009) concluded that tour guiding demands a high degree of emotional labour resulting from a range of interpersonal interactions. In one of the few investigations of emotional labour amongst adventure guides, Sharpe (2005) identified high levels of emotion work stemming from client interactions. Zapf (2002) argued that emotional labour is more important in the service industry than other sectors and recent studies have documented the emotional labour demands of front-line tourism workers (e.g., Constanti \& Gibbs, 2005; Guerrier \& Adib, 2003). Research also indicates that stress associated with performing emotional labour can undermine employees' mental well-being (e.g., Brotheridge \& Grandey, 2002; Brotheridge \& Lee, 2003; Erickson \& Wharton, 1997; Liu, Perrewe, Hochwarter, \& Kacmar, 2004; Lv, Shi, \& Hui, 2012; Morris \& Feldman, 1997; Pugliesi, 1999; Zapf \& Holz, 2006). Nevertheless, emotional aspects of tourism guiding have generally been narrowly examined in terms of interactions with clients, rather than employers, and sources of stress and emotions in the adventure guiding context remains under researched. Due to the significant role that guides play in promoting tourist satisfaction (Ap \& Wong, 2001) and the high emotional labour demands placed on guides (e.g., Sharpe, 2005), emotional experiences and sources of stress for adventure tourism guides, particularly with regard to employer-guide interactions, merits further investigation.

\subsection{The nature of adventure tourism guiding}

It is likely that adventure tourism guiding may present unique sources of stress and emotions due to the nature of this job. Adventure guides often work seasonally across distinct cultural settings. River guides, for example, may work in Europe or North America from April through September and then travel to South America or Australasia for the summer season from October to April. The reverse pattern is often evident for skiing or snowboarding guides. Mountain guides also travel frequently as a matter of course and must often interact with diverse cultures and local operators or officials. Research indicates that while individual appraisals of these novel cultural situations dictate how positively or negatively they will be interpreted, operating in unfamiliar cultural contexts is generally more stressful and results in increased psychological adjustment problems (e.g., Babiker, Cox, \& Miller, 1980; Berno \& Ward, 2005).

Although many front-line staff contend with seasonality and intercultural issues, adventure guiding often requires increased levels of technical skills and personal responsibility (e.g., for clients, safety, trip planning, logistics); specialised qualification or training requirements; extended exposure to clients and other guides (e.g., via shared living quarters; camping); and may necessitate quickly learning and acclimatising to novel outdoor environments and operational systems. Many adventure companies also operate on smaller scales than large hospitality enterprises, and thus require guides to occupy multiple roles within a company (e.g., guide, operations manager, marketing and sales, human resources management, equipment manager, mechanic) and potentially live on-site. These situations can lead to complex dual relationships with employers and peers. 
Coupled with the heightened levels of risk and uncertainty inherent in adventure activities, these factors suggest that adventure tourism guides may encounter unique sources of stress and distinct motivational and emotional responses. As one of the "most challenging effects of globalisation in tourism is the need to manage an increasingly culturally diverse workforce and market" (Moscardo, 2004, p. 7), psychological investigations of adventure guiding experiences are necessary to promote effective management strategies. Understanding the complex motivational and emotional aspects of adventure guiding can help prevent undesired outcomes, such as guide and tourist dissatisfaction or unsafe guiding practices, as well as improving operational and financial success, risk management, and human resource management for seasonal, new, or foreign staff.

\subsection{Psychological frameworks informing the study}

Despite the volume of literature devoted to emotional experiences across general and applied psychology, as well as consumer behaviour research (e.g., Richins, 1997), there has been considerable debate and little agreement as to what the basic human emotions are (e.g., Bagozzi, Gopinath, \& Nyer, 1999; Laros \& Steenkamp, 2005). Extensive catalogues of possible emotions and a number of different theoretical approaches have been explored in psychological and consumer behaviour research (e.g., Izard, 1991; Johnson \& Stewart, 2005; Oliver, 1993). Richins (1997) proposed that emotions are context-specific and that emotion scales should be situationally appropriate. Her work also found that negative emotions are rarely important or reported in consumer situations. As the current study investigated the other side of the 'consumptive coin' by exploring stressors and resulting positive and negative emotions in the guiding context, a contextually appropriate framework encompassing the full range of potential emotional experiences was essential. Thus, basic psychological frameworks beyond those traditionally employed in tourism and consumer behaviour research informed this study.

Stress and coping literature provides a cognitive appraisal explanation of why we experience events as positive or negative (e.g., as anxiety or excitement). Our emotional responses result from cognitive appraisals of the following factors (Lazarus, 1991): goal relevance (i.e., emotions only result if goals are of concern or relevance); goal congruence (i.e., positive emotions result from movement towards our goals, while negative emotions result from movement away from our goals); and ego involvement (i.e., degree to which a goal or event reflects on the individual). A large body of empirical research has supported the key role of perceived personal control and goal states on emotional responses, and demonstrated the interrelatedness of cognitive, emotive, and motivational systems with regard to goal states (e.g., Dickson, 2006; Hardy, Jones, \& Gould, 1996; Monat \& Lazarus, 1991). Stress and coping research indicates that appraisals of current goal states are crucial to understanding and predicting how a person will experience external events.

Reversal theory (e.g., Apter, 1982, 2001) is a psychological theory that further develops our understanding of individuals' current goal states. This model explains the structure of subjective experiences and emotions by identifying a range of governing goal states. It posits that our current goal state or 'frame of mind' (i.e., our metamotivational state) dictates the way that we interpret somatic feelings and interpersonal transactions (Apter, 1982, 2001). An extensive body of research has demonstrated support for the structural framework of experience proposed by reversal theory (see Apter, 2001 for a review). Evidence from clinical case histories, phenomenological, psychometric, experimental and psychophysiological studies were influential in the formation and validation of this model, and it has been applied to many areas of psychology, including smoking addiction (O'Connell, Cook, Gerkovich, Potocky, \& Swan, 1990), responses to stress (Martin, Kuiper, Olinger, \&
Table 1

Proposed motivational state pairs in reversal theory.

\begin{tabular}{ll}
\hline Telic: & Paratelic: \\
serious, outcome-oriented, & playful, process-oriented, \\
$\quad$ arousal-avoidant & arousal-seeking \\
Conformist: & Negativistic: \\
rule-abiding & rebellious \\
Mastery: & Sympathy: \\
domination-oriented & relationship-oriented \\
Autic: & Alloic: \\
self-focused, concern for self & other-focused, concern for others \\
\hline
\end{tabular}

Dobbin, 1987), the nature of play (Kerr \& Apter, 1991), the enjoyment of humour (Wyer \& Collins, 1992), soccer hooliganism (Kerr, 1994) and cardiovascular risk (Svebak, Nordby, \& Ohman, 1987). In addition to development in general psychology, reversal theory has been advanced specifically in the contexts of sport and leisure (e.g., Apter, 1989, 1992; Chirivella \& Mayor, 1994; Cogan \& Brown, 1999; Florenthal \& Shoham, 2001; Kerr, 1987, 1989, 1991, 1994, 1999; Kerr \& Cox, 1991; Kerr, Fujiyama, \& Campano, 2002; Legrand \& Apter, 2004; Pain \& Kerr, 2004; Svebak \& Kerr, 1989; Trimpop, Kirkcaldy, \& Kerr, 1996); exercise (e.g., Kerr, 2001); and adventure activities in particular (Apter \& Batler, 1997; Houge Mackenzie et al., 2011; Kerr, 2007; Thatcher, Reeves, Dorling, \& Palmer, 2003).

Reversal theory proposes four pairs of metamotivational states that influence felt emotions (see Table 1), a number of which are also included in consumer behaviour models (e.g., anger, shame, pride, fear/anxiety; Richins, 1997). A person in the telic state is primarily serious, goal-oriented and arousal-avoidant, while feeling spontaneous, playful and arousal-seeking in the opposing paratelic state. In the conformist state, a person is compliant and agreeable, and rebellious, unconventional and defiant in the opposing negativistic state. A person in the mastery state is competitive and dominating, while in the sympathy state she or he has a desire for harmony and cooperation. In the autic state, a person is egoistic and concerned with the self, while feeling altruistic and concerned with others in the alloic state. People are predicted to reverse between these paired motivational states during everyday life, producing significant changes in a person's motivations and emotional experience. Different combinations of motivational states result in different emotional outcomes; reversal theory predicts 16 primary emotions which are produced by different state combinations (see Table 2). Stress and negative emotions result from a mismatch between a person's preferred way of feeling (dictated by their current motivational state) and their current experience.

Reversal theory distinguishes two types of emotions: somatic emotions, which are based on an individual's interpretation of bodily arousal (termed felt arousal), and transactional emotions, which are based on an individual's interpretation of the perceived outcome (gain or loss) of transactions with other people or objects (termed felt transactional outcome). For each motivational state combination (e.g., telic-mastery) there is a preferred level of felt

Table 2

Somatic and transactional state combinations and the resulting 16 primary emotions.

\begin{tabular}{|c|c|c|}
\hline State combination & Pleasant & Unpleasant \\
\hline \multicolumn{3}{|l|}{ Somatic emotions } \\
\hline Telic-conformity & relaxation & anxiety \\
\hline Telic-negativism & placidity & anger \\
\hline Paratelic-conformity & excitement & boredom \\
\hline Paratelic-negativism & provocativeness & sullenness \\
\hline \multicolumn{3}{|l|}{ Transactional emotions } \\
\hline Autic-mastery & pride & humiliation \\
\hline Autic-sympathy & gratitude & resentment \\
\hline Alloic-mastery & modesty & shame \\
\hline Alloic-sympathy & virtue & guilt \\
\hline
\end{tabular}


arousal (e.g., low arousal) or felt transactional outcome (e.g., dominance). Pleasant emotions are experienced when preferred levels of these variables match those actually experienced by a person at any time. If a mismatch between experienced and preferred feelings occurs, unpleasant emotions result. The degree to which this mismatching occurs is experienced as tension stress. The greater the mismatch between felt and preferred levels of felt arousal or felt transactional outcome, the greater the level of tension stress. Attempts to cope with tension stress, by changing levels of the relevant variable, is termed effort stress in reversal theory (Svebak \& Apter, 1997).

\subsection{Study aims}

The reviewed literature indicated that improved understanding of adventure tourism guiding experiences over time was needed from an 'insiders' perspective. Adventure tourism research could also benefit from the integration of established psychological theory to further develop our understanding of the mechanisms governing guides' subjective experiences. Accordingly, the purpose of this study was to provide an extended 'insiders' perspective of adventure tourism guiding experiences that employed an established psychological framework to strengthen data analysis. The case study presented here extends previous literature that has focused primarily on guide-to-client interactions by qualitatively detailing an adventure tourism guide's experiences in relation to employer-guide interactions, and identifying motivational reversals, accompanying emotions, and stress responses that occurred throughout these experiences. This study also explores the implications of these psychological fluctuations for guides and adventure operators. While reversal theory constructs have been previously described and compared to conceptual frameworks in tourism literature (Gyimothy \& Mykletun, 2004), no research has explicitly used reversal theory as the primary basis to explain tourism guiding experiences. Based on the identified gaps in the literature, this study had the following aims:

1. To provide an in-depth 'insiders' account of adventure tourism guiding experiences over the course of a guiding season.

2. To identify sources of stress and emotions in the employer-guide relationship through the use of an established psychological framework (reversal theory).

3. To make recommendations for tourism practitioners that might alleviate (or mitigate) stressful experiences between employers and guides.

4. To enrich future investigations of tour guiding experiences both methodologically and theoretically.

\section{Methodology}

While not one of the primary study aims, this project also contributed an emergent methodological approach to the tourism discourse: autoethnography. This method was chosen due to the exploratory nature of this study, the lack of previous research in this area, and the unique 'insider' insights it could yield. It also offered the opportunity for an in-depth longitudinal analysis of stress, emotions, and interpersonal transactions in adventure guiding. This approach contrasted with previous ethnographic research that has focused on guide-to-client interactions and social constructions of adventure experiences (e.g., Holyfield \& Jonas, 2003; Jonas, 1999; Sharpe, 2005).

\subsection{Autoethnographic approaches}

Recent tourism research reflects the emergence of more interpretative and critical forms of enquiry. These include a range of alternatives to dominant positivist approaches, such as autoethnography. Participatory research and experimental writing are being embraced and narrative methods increasingly emphasise reflexivity and personal voices, including those of researchers themselves. Autoethnography is an important part of this methodological shift that Denzin and Lincoln (1994) identified as the fifth moment in the history of qualitative research. A central distinction between autoethnography and traditional methodologies is that researcher biases and reflexivity are openly acknowledged and discussed in autoethnography. In contrast to ethnography, in which the researcher attempts to become an insider, the researcher in autoethnographical enquiry is the insider who provides unique insights into personal and emotional lifeworlds (Ateljevic, Pritchard, \& Morgan, 2007). Critical literature regarding situated methodologies supports the use of emergent methods such as autoethnography to enhance tourism research (e.g., Hall, 2004). Notwithstanding this paradigmatic shift, scholars such as Hall (2004, pp. 140, 142) have critiqued continued resistance towards autoethnographical methods in tourism research:

Accounts of any discipline and of research within that field of study are situated. That is 'they depend upon the point of view of the author, which in turn reflects how he/she is positioned intellectually, politically, socially' (Barnes \& Sheppard, 2000, p.6). However, how often does one read research which explicitly recognizes its situatedness in tourism? Despite the postmodern recognition of the absence of absolutes, this does not seem to have been widely translated into the representation and reading of tourism research and scholarship... Think of how few times such an expression of the first person is included in academic writing as expressed in the majority of tourism journals and text. Indeed, academic writing in the third person conveys and impression of objectivity and scientific rationality which is almost the antithesis of the realisations of reflexive modernity. If one where to submit an article written solely in the first person to most academic tourism journals, the likelihood is that it would not be accepted.

More recently, Anderson and Austin (2012) demonstrated the potential of autoethnography to capture unique insights in leisure research and this approach has been successfully employed to explore adventure motivations (Buckley, 2012), mountain guiding experiences (Beedie, 2003), and whitewater rafting interactions (Jonas, Stewart, \& Larkin, 2003). Buckley's (2012) autoethnographical study of adventure tourism motivations identified the construct of 'rush' as an essential tourism motive based on autoethnographical data gathered by an experienced adventure tourism participant and guide. The current study used a similar methodology in that the lead author conducted a focused autoethnographical study of her guiding experiences in a foreign country. However, this investigation applied an established psychological framework (reversal theory) to deductively understand motivations and emotions experienced during adventure guiding, rather than using autoethnographical data inductively to support a new motivational construct. This approach was used to convey an authentic, emotionally-nuanced account of her adventure tourism guiding experiences, while interpreting that experience through a critical lens. Thus, the present study demonstrated a novel methodological application of autoethnography to tourism research.

An analytical autoethnographical approach, which aligns with traditional social science epistemologies and theoretical analyses, guided the current study (Snow, Morrill, \& Anderson, 2003). However, the presentation of data also uses evocative autoethnography techniques to stimulate emotional empathy and perspectivetaking (Anderson \& Austin, 2012). This method allows readers to empathise and thereby gain a fuller understanding of the guiding 
experience itself and the theoretical explanations provided. The autoethnographer also adhered to the following methodological guidelines: complete member status of researcher; analytic reflexivity; narrative visibility of the researcher's self; dialogue with informants beyond the self; and commitment to theoretical analysis (Anderson, 2006).

\subsection{Thick descriptions: the autoethnographer, data collection procedures, and analysis}

Rather than judging the 'representativeness' of qualitative data in terms of objectivist criteria such as frequency or variability, the value of qualitative research is largely dependent on providing sufficient 'thick descriptions' of the researcher(s), data collection, and analysis procedures to establish trustworthiness (e.g., Denzin \& Lincoln, 2005). Lincoln and Guba's (1985) recommendations for trustworthiness include the need to establish credibility, transferability, dependability, and confirmability. To address these criteria, the investigators attempted to demonstrate a true picture of the phenomenon being presented; provide sufficient detail of the context of the fieldwork so that findings could be applied to a similar setting and/or replicated; and demonstrate that findings emerged from the data through theoretical analysis and triangulation.

Sparkes (2000) maintained that autoethnography is at the boundaries of academic research because it does not easily adhere to traditional criteria used to judge qualitative investigations. While a number of scholars have recently proposed and discussed criteria for evaluating autoethnographical research (e.g., Anderson, 2006; Ellis \& Bochner, 2000; Richardson \& St. Pierre, 2005; Schwandt, 1996; Smith \& Hodkinson, 2005) the challenge to develop flexible criteria relevant to different types of research remains (e.g., Anderson \& Austin, 2012; Garrett \& Hodkinson, 1999). Garrett and Hodkinson (1999) suggested that traditional criteria used to judge qualitative research in general may not be appropriate for autoethnography. For example, evocative autoethnographers reject traditional 'objectivist' criteria such as validity, reliability, and generalisability and characterise their work as the "epistemology of emotion" (Denzin, 1997, p. 228). These researchers argue that their work should be evaluated by criteria such as coherence, texture of argument, interpretive insight, rhetorical force, and beauty (e.g., Schwandt, 1996). In the current study, we employed a more conservative approach to autoethnography: realist 'analytical' autoethnography. This approach combines evocative writing and a visible researcher-self with an explicit analytical agenda and places the researcher in context with other group members (Anderson, 2006). The autoethnographer also sought to clearly demonstrate reflexivity, personal lenses and biases, study boundaries, and limitations of the current work (Duncan, 2004) through transparency and thick descriptions of the autoethnographer and research process.

Data was collected in the form of daily journal entries and emails recorded during the lead author's sixteen week employment as an adventure guide in South America. These data conveyed indepth details of her whitewater riverboard (also termed sledging or hydrospeed) guiding experiences. The lead author was a whitewater riverboarding guide with nine years of experience in western countries prior to conducting the study. She was also proficient in Spanish and had a background in psychological research and adventure tourism management.

The lead author first made contact with her future employer via email after a fellow river guide, who had previously worked for the employer, recommended contacting him for employment in South America. The only prior knowledge the author had of this company was based on the company website and a few brief emails from her river colleague indicating that the documentation and permits required to guide in that area were complex and bureaucratic. The future employer responded by inviting her to travel immediately to his town and prepare for the upcoming annual river test required of all whitewater guides in that municipality. Two days later, the lead author embarked on a $30 \mathrm{~h}$ trip to the town (from a neighbouring South American country) and initially entered into an informal agreement to receive accommodation and work for the season upon passing the local exam. It was expected that she would be the primary on-call guide for his company throughout the summer season (December to April). Upon passing her exam, she obtained all required work permits and documentation to guide and legally work in that country.

Textual analysis of each journal entry and email was conducted by coding data for motivational states and emotions with the Metamotivational State Coding Schedule (O'Connell, Potocky, Cook, \& Gerkovich, 1991), as well as emergent themes. Raw quotes were grouped together based on motivational state combinations and resulting somatic and transactional emotions, and then reanalysed to identify common patterns, discrepancies, or unique themes. For example, "I felt stressed out [about the river exam]" was coded as the serious, rule-abiding (telic-conformity) state combination with anxiety as the accompanying emotion. "I am angry at Juan and nervous because I haven't gotten my [exam] results" was coded as anger and anxiety resulting from a reversal between the serious, rebellious (telic-negativism) state combination (anger) and the serious, rule-abiding (telic-conformity) state combination (anxiety). "It's also been really nice to get to know his family and learn about a different culture, but also see how similar we really are...We laugh a lot" was coded as the playful, rule-abiding state combination (paratelic-conformity) with excitement as the resulting emotion, and the self-focused, relationship-oriented state combination (autic-sympathy) with gratitude as the resulting emotion. Data was also organised chronologically within each motivational state combination and analysed for patterns over time. This method allowed for deductive analysis of established theoretical constructs (e.g., metamotivational state(s), hedonic tone (experience pleasure), reversals, pleasant and unpleasant emotions), while also allowing inductive themes to emerge from the data (i.e., safety issues, poor equipment, communication problems).

The current methodology mirrors recent consumer behaviour research approaches, such Coghlan and Pearce's (2009) study in which tourists recorded motivations, overall affect levels, and feelings with regard to daily activities in diaries. These authors advocated the use of time-based, sequential records of emotional states to analyse tourism experiences, rather than post-trip global measures that only partially reflect the emotional variability revealed in daily recordings. Our study used a conceptually similar approach by linking activities, interpersonal interactions, and emotional responses in daily diary entries. In these entries, the autoethnographer focused on motivational and emotional aspects of her experiences and the impact of interactions and events on her affective states. Rather than merely logging daily activities, care was taken to record detailed emotional aspects of guiding experiences and contextual details such as time and place. An advantage afforded by autoethnography in this context was the ability to collect sequential data over a much longer time span than traditional studies (approximately 100 days longer than Coghlan and Pearce's (2009) study) and thereby explore psychological nuances of an experience longitudinally. This approach provided a counterpoint to the briefer, often single time point, external perspectives provided in past studies. The autoethnographer's psychological background also enabled to her record in detail key aspects of her experience as they unfolded (e.g., intensity of arousal levels associated with emotional states; positive versus negative hedonic tones; the range of primary emotions from general psychology; and a range of motivational states) and examine these patterns over 
time. The reversal theory approach to coding and identifying emotions also provided a systematic and rigorous approach to understanding emotional experiences via in situ coding of fluctuations in felt emotions in detailed, chronological records.

The comprehensive content analysis review process undertaken in the present study was consistent with the processes carried out in several previous reversal theory-based qualitative studies (e.g., Bellew \& Thatcher, 2002; Hudson \& Walker, 2002; Legrand \& LeScanff, 2003; Males, Kerr, \& Gerkovich, 1998). Data auditing was used to minimise selective reporting and cognitive bias during data analysis. The second author (an expert in reversal theory and qualitative research) substantiated the lead author's analyses by carefully reviewing all raw data sources and independently identifying common themes. Both authors repeatedly reviewed the entire data set to ensure that representative quotes were chosen to display common themes and patterns. As experienced qualitative researchers, both authors were aware of potential biases in the data collection and analysis process, and endeavoured to guard against these through reflexivity, continual self-critique, and reference to theoretical coding tools (e.g., e.g., Denzin \& Lincoln, 2005; O'Connell et al., 1991). A third independent person (experienced in qualitative research and familiar with reversal theory) acted as an external data auditor reviewing the authors' 'audit trail', as recommended by Lincoln and Guba (1985). Triangular consensus amongst the two authors and the external auditor helped to minimise possible researcher bias and establish overall trustworthiness in the data analysis procedures (Biddle, Markland, Lilbourn, Chatzisarantis, \& Sparkes, 2001; Gould, Jackson, \& Finch, 1993).

\section{Results and discussion}

In this section, raw data are presented chronologically and thematically to facilitate contextual understanding of the adventure guiding experience as it unfolded over the sixteen week river season, and to highlight reoccurring emotional patterns. Verbatim data (autoethnographical journal and email excerpts) appear in italics. All data presented is drawn from journal entries unless denoted as 'email' data in brackets following the quote. Following the presentation of raw data, theoretical analyses are presented and discussed.

\subsection{Arrival and certification}

When we finally arrived in [town] after 30 hours, it was pissing down with rain and freezing ... Juan, ${ }^{1}$ my future boss who has turned out to be a very generous and hospitable man, picked us up and took us to stay in his cabin behind his house. I had [about 10 days] to prepare for the yearly river exam here which is required if you want to guide in [town].

Awoke very tired and went to the local council to get all my documents together. My god what they asked for here! I had to get a psychological exam which was an expensive rip-off...five minutes of picking colors...The medical [exam] took three days of going back to the hospital...as all the doctors were out on strike; finally the doctor came, met me, and signed a clearance letter without examining me. What a farce. I also had to get letters, proof of certification courses, even my school transcript, just to take the annual river exam here. I had to buy a bunch of useless stuff for a first aid kit that I would never use...I started getting quite annoyed at...all of these regulations.... It seemed more like a good business for the [local council] rather than good safety practices.

\footnotetext{
1 All names are pseudonyms.
}

I wanted to impress [other guides and Juan] by being able to do everything perfectly straight away; yet here I was feeling nervous and unsure of myself and my abilities like I did when I first became a guide.

We are staying with some very nice people that own an adventure tourism company... Juan has put us up in his rental cabin at his house for free since we arrived and they keep feeding us as well! ...They are so nice and have looked after us really well, even giving me most of the gear I need to work on the river here... They are looking after us well so we will probably have Christmas and New Years here with them if I hopefully pass my test tomorrow. [Email]

I've been sick for about a week now and unable to go on the river some days...not sure why as I'm sleeping a lot...I felt stressed out [about the river exam] because I didn't want to let my boss down after all he had done for me with giving us food, accommodation, basically taking us into his home with him and his family. He looked after us just like family... I didn't want to let him down.

\subsection{Employer-to-guide interactions: dual relationships}

I am angry at Juan and nervous because I haven't gotten my [exam] results... and yet today he asked me to guide three people down the river [alone]... I still don't know the lines so it was a nightmare. I didn't want to do it but felt I had to out of obligation, so... I made Pete [another guide] come along with me just for extra safety...It was a nightmare...I took everyone down the wrong side of an island. Pete almost got entrapped...two people flipped off their boards and panicked - all because I took them down the wrong line. I was meant to keep them safe and I led them into danger...I bawled my eyes out after the clients left. I felt so ashamed and embarrassed that I didn't ever want to guide again... I also felt angry at my boss for putting me in that position when I wasn't ready, but I couldn't say no because I was indebted to him for his kindness and didn't want to let him down.

I'm starting to feel happier and more settled here now that my guiding confidence has gone up and all my visa legalities have finally been sorted out. The only thing that has kept me from totally relaxing is the fact that we're still in my boss's house and feel that we need to move out but it's impossible to find a place. But it's also been really nice to get to know his family and learn about a different culture, but also see how similar we really are...We laugh a lot and have long, hilarious dinners together... [Juan] says we are 'good therapy' for him. He also says he likes [foreign] guides for their work ethic... I'm off to join Juan and the family for our nightly laugh-fest over [inter]cultural miscommunications.

[Recently] I have had good trips but also continued frustration and anxiety. For example, this morning I got a call [to guide a] trip solo...with three "gringos." When I asked about my safety guide, Juan said, "They are gringos," as though gringos are naturally so good in the water that we don't need to follow regulations... Then he said, "Do you want me to call another guide [instead]?” ...Oh, no pressure...This seems to happen all the time. He just makes his own rules on safety, and if you question the number of guides or the minimum age of clients, it's like you're not doing good work for the business. Juan will say how he can't operate with more staff, or it's unnecessary and [act as though] he's doing you a favour [by giving you work]...or [say] how his son the 'amazing guide' could take 10 people down the river on his own. So it's also implying that you are not a very good guide if you're trying to be safe. Partly it's all these price wars here...I don't see how operators can run safe trips, but tourists just look at the price here. 
I'm upset that my boss seems to think it's okay that I get everything organised with no extra help or pay. Today he rings and says, "Why have you not called for the [wetsuit] sizes?" For one, the sizes are always wrong anyway...And two...I didn't even know he [expected] me to call...as he speaks really fast [colloquial] Spanish and I can't understand him half of the time on the phone... Yesterday I was sick...my trip was terrible...We got out before [the last big rapid]. Juan asked why we got out. Because [the clients] were [very poor swimmers] and I'm guiding alone, which I'm starting to suspect is illegal even though he says it's not, and that's freaking me out. It's not his [butt] on the line if someone dies. It's my call. So yeah, I'm pretty pissed off right now.

Today I packed [wetsuit] sizes for three "men." At the last minute, Juan called to change sizes. Then I found out why. It was a dad, an 11 and 13-year-old. Our minimum age is 15. Fair enough he didn't know beforehand, but I still had to take them on my own and then disappoint them when I took two out after the first few rapids and towed the other for the next 7 kilometers. They just won't say no to anyone here who is willing to pay for a trip. They definitely need an operations manager who isn't the owner. I have tried to make suggestions and Juan just seemed to get offended and say it wouldn't work...I'm forced to give people gear that doesn't fit. I find this so embarrassing. We had a group with all the wrong sizes and I had to just pretend that the suits fit fine and was just cringing with embarrassment as [Juan] taped fins to peoples' feet so they wouldn't fall off. How unprofessional are we? But Juan acts like it's no big deal. I tell him we would save so much time [doing it another way], but no, he got angry and said I have to adjust to how they do things in [country]. It's not him who has to adjust...I wasn't being condescending at all, just making a suggestion, so I definitely felt upset and taken aback [at his reaction].

I'm pissed off as I waited half an hour for this trip and Juan just called and said, "I'll be there [in an hour]" with no respect for my time... I'll be waiting two hours for this trip and won't get paid any more. He has too [many adventure activities] to do any one thing well. I constantly have conflicting feelings of gratitude to him for being so helpful with my [work] visa, giving me gear, a job, hosting us in his house, and looking after us like family, and at the same time I get so frustrated at the way he runs his business (or doesn't). But then I always feel guilty or ungrateful if I question things... or don't agree with his safety calls... he has done so much for [me]...This is the hard part about dual roles. I like the man, but once business and money get involved, it complicates things. I guess no one is perfect.

I ask [Juan] how old [the clients] are, he says he doesn't know...I get frustrated when a load of kids show up and we are always short at least one guide or a safety boat. It's just not a safe trip...I feel annoyed and angry with him for putting me in that situation where it's hard to say no to your clients or him... After the trip it's always more relaxed and happy... but it's frustrating that he always wants someone to blame if sizes are wrong or if people don't show up...He doesn't communicate but expects you to still know and anticipate everything.

Juan... micromanages you and you can never please him because you don't know what he wants.

We just had our first [country] New Year with the family we are living with. Hilarious is all I can say. We had dinner at home with them and then went to watch the fireworks and dance in the town square. It was so nice - they feel like our real family and it was so fun to celebrate with them. [Email]

\subsection{Withdrawal and departure}

I was worried to...tell [Juan] I'm leaving [before the end of the season], but he reacted better than I thought. Now I just try and shut up and not say anything about...his organisational system...but it still annoys and frustrates me constantly operating outside the regulations of the area in a way that is so disorganized...I'm still frustrated with how he tells me...he'll organize [the gear] because he doesn't trust me to do it. [but then] blames me if the gear doesn't fit... But he did recognise [my hard work] today when I was the only guide [on the trip] actually working - that felt good.

Now I'm trying to take a step back, not care, and just go with it. If Juan wants to do things this way, it's not my fault if gear doesn't fit or people are upset. It's not my business.

I felt angry that Juan didn't want to pay our [safety] kayaker today when a lot of [clients] didn't show up. But only two weeks left so I'll keep my mouth shut, try not to care too much about anything, and enjoy it without getting too stressed out or frustrated.

[You] can't do a good job [here] as you never know all the information: sizes, times, how many [clients], and what is going on... Only 10 days left.

We got out [of the river] early [today] to avoid the river inspectors...I think...[Juan is] getting fined [for unregistered trips]. I was the only one Juan didn't tell, which makes me wonder if he's hiding [something] from me. He kept saying, "What a beautiful place to get out of the river,"... I'm thinking, "Yeah, whatever... You got out here just to be sneaky, not because it's so beautiful." He must not want me to know...Maybe he knows I like to conform to the rules. Who knows? Three days left.

I feel more relaxed with everyone now that I am leaving... Forget about the past annoyances, just enjoy my trips and surf waves...I'm not so concerned with what Juan or the other guides think. I just want to be on good terms with everyone and enjoy my last few days. I feel....ready to leave. Not really sad...In fact, I feel like life here has become boring... I'm not sure why; there is a lot to do around here, but it just feels not that exciting or interesting, like our life is pretty routine and nothing much happens outside of the river work.

Living here has been full of ups and downs. On one hand I've loved meeting some amazing people and forming a kind of family with Juan and his family. They were so generous and welcoming of us into their home and really seemed to like having us as part of their lives...We had such great times laughing, having family dinners, hanging out at the shop...There was always that other side when I was working for Juan and would get so stressed out and frustrated at how he ran things or how disorganised or unsafe trips seemed to be...I always felt these conflicting emotions of gratitude and affection towards him and his family... and also anger at being put in situations I was uncomfortable with or having to do things unprofessionally...I've grown a lot as a guide and gained a much broader perspective on guiding, management, and how [adventure guiding] work[s] in different countries.

\subsection{Theoretical analysis: stress and emotions}

In order to enable a more intuitive understanding of the theoretical analysis provided, motivational states in this section are referred to by their defining characteristics, rather the labels traditionally used in reversal theory (i.e., the telic state is serious and the paratelic state is playful; the conformist state is rule-abiding 
and the negativistic state is rebellious; the mastery state is domination-oriented and the sympathy state is relationship-oriented; the autic state is self-focused and the alloic state is others-focused). States associated with an emotional response or specific quote are identified parenthetically. Data analysis revealed that adventure guiding was a dynamic experience characterised by a range of both pleasant and unpleasant somatic and transactional emotions. Unpleasant emotions reflected the fact that some aspects of the adventure guiding experience were stressful. What transpired was a kind of 'dual' relationship between the guide and Juan, her employer, with the live-in/hosting situation generally inducing pleasant emotions and the work context generally provoking unpleasant emotions and stress. For example, her experience began with pleasant feelings of gratitude (self-focused, relationshiporiented states) towards the new employer (Juan) and his hospitality ("who has turned out to be a very generous and hospitable man"; "They are so nice and have looked after us really well"). However, in the work environment, these pleasant feelings were superseded by high arousal anxiety and (tension) stress experienced in the serious state due to a number of factors: the perfunctory certification procedures ("the doctor came, met me, and signed a clearance letter without examining me"; "I started getting quite annoyed at...all of these regulations"); the desire to impress a new employer ("I wanted to impress [them] by being able to do everything perfectly straight away"); and an unfamiliar river environment ("I still don't know the lines").

This was illustrated by one of the guide's first experiences on the river with a group of tourists. She was nervous about escorting the group because she was still awaiting her exam results and was therefore technically unqualified. She was not as familiar with the river as she would have liked and asked another guide (Pete) to join the trip. The river descent turned out to be particularly stressful ("It was a nightmare...I took everyone down the wrong side of an island. Pete almost got entrapped...two people flipped off their boards and panicked"; "I was meant to keep them safe and I led them into danger"). After this "nightmare" experience in which her interactions with the tourists went badly (low felt transactional outcome), she was very upset. She experienced shame (othersfocused, domination-oriented states) and embarrassment (humiliation; self-focused, domination-oriented states) ("I felt so ashamed and embarrassed that I didn't ever want to guide again"). Out of her usual regulated and well-organised guiding environment, she also felt anger (high arousal in the serious, rule-abiding states) towards Juan ("I also felt angry at my boss for putting me in that position when I wasn't ready").

As time went on, her hedonic tone (experienced pleasure) improved ("I'm starting to feel happier") when her visa problems were solved and she regained some of her confidence on the river. She was still living with the family and while this "has kept me from totally relaxing", she was able to enjoy her interactions with the family ("it's also been really nice to get to know his family"). The "hilarious" dinners they had in the evening were especially enjoyable. Here, the humour involved ("our nightly laugh-fest over [inter]cultural miscommunications") meant that she could reverse from the serious activities of river guiding to playful, fun-oriented social interactions. In a situation with few options for coping (effort stress) with the (tension) stress associated with her work situation, interacting with the family in the evenings enabled her to cope with her (tension) stress to some extent.

However, the river guiding work environment continued to be problematic and transactions with Juan became increasingly punctuated by negative emotions as the season progressed. For example, the foreign guide expected more 'choreographed' and organised adventure tours due to her previous guiding experiences in other countries, and increasingly came to view Juan's spontaneous and unstructured management style as irresponsible and unprofessional ("At the last minute, Juan called to change sizes. Then I found out why. It was a dad, an 11 and 13-year-old. Our minimum age is 15"; "We had a group with all the wrong sizes and I had to just pretend that the suits fit fine and was just cringing with embarrassment as [Juan] taped fins to peoples' feet so they wouldn't fall off"; "How unprofessional are we?"; "They definitely need an operations manager who isn't the owner").

Juan's approach to adventure tourism and management increased the guide's (tension) stress and she continued to experience anger (high arousal in the serious, rule-abiding states) ("I feel annoyed and angry with him for putting me in that situation") and resentment (low felt transactional outcome in the self-focused, relationship-oriented states) ("I'm pretty pissed off right now"; "I'm upset that my boss seems to think it's okay that I get everything organised with no extra help or pay").

Intercultural differences were also at focus in the employer's attitude towards local regulations and safety, and were an additional source of stress and negative emotions for the guide ("He just makes his own rules on safety"; "I'm guiding alone which I'm starting to suspect is illegal even though he says it's not, and that's freaking me out"; "So it's also implying that you are not a very good guide if you're trying to be safe"). Juan defied local regulations and instead appeared to rely on previous experience, intuition, economic logic, and sometimes necessity, to make safety decisions. This was a definite point of contention for the foreign guide who was motivated to abide by local regulations and her notions of best river guiding practice. Despite being a capable Spanish speaker, she also experienced intercultural difficulties resulting from poor employer-guide communications, which added to her stress levels and unpleasant emotions ("I didn't even know he [expected] me to call...as he speaks really fast [colloquial] Spanish and I can't understand him half of the time on the phone"; "He doesn't communicate but expects you to still know and anticipate everything"). Attempts by the guide to persuade Juan to examine or adopt other organisational approaches generally failed and produced further unpleasant experiences: "I tell him we would save so much time [doing it another way], but no, he got angry and said I have to adjust to how they do things in [country]. It's not him who has to adjust...I wasn't being condescending at all, just making a suggestion, but I definitely felt upset and taken aback [at his reaction]."

Once the river guide decided to depart, different motivational patterns emerged and she underwent significant changes in her emotional experiences. Her serious approach to guiding and concern for safety regulations appeared to dissipate and her unpleasant anxiety and anger converted to pleasant feelings of relaxation (low arousal in the serious, rule-abiding states) and placidity (serious, rebellious states) ("I feel more relaxed with everyone"). She became more playful and spontaneous, and was mostly concerned with the pleasures of enjoying the river ("just enjoy my trips and surf waves"). She also became much less focused on herself and doing things 'her way' (self-focused, dominationoriented states), and wanted to be friendly and cooperative with everyone (other-focused, relationship-oriented states; "Forget about the past annoyances"; "I just want to be on good terms with everyone"). In reversal theory terms, a reduction in previous high levels of arousal (anxiety to relaxation) and a reversal from the serious to the playful state occurred. Reversals from the self-focused to the other-focused state, and from the domination-oriented to the relationship-oriented state, were also evident. These reversals likely took place as a result of the guide's frustration with Juan's operating style. These psychological changes were generally positive and her level of hedonic tone increased. However, shortly after this stage, there was one negative effect of these changes reported by the guide. She began to experience feelings of boredom (low arousal in 
the playful, rule-abiding state; "life here has become boring"; "it just feels not that exciting or interesting"). Boredom can also be a low arousal form of (tension) stress and this became an additional factor in her motivation to leave.

In summary, data analysis revealed that adventure guiding experiences contained numerous sources of stress and intense emotions resulting from: communication difficulties (due to language and cultural differences); lack of information provided to staff (e.g., guide expectations, trip details); perceived inequities in guide expectations (e.g., foreign versus local) and pay; pressure to guide with: inadequate ratios, inappropriate equipment, and unsuitable client groups; lack of trust between the employer and guide; dual relationships which promoted a sense of obligation; and misunderstandings due to cultural or language differences. These factors contributed to a generally unpleasant, stressful experience in the work context and provoked feelings of anxiety, frustration, anger, and resentment. In stark contrast, the live-in/ hosting situation was generally experienced as pleasant, with non-stressful interactions (shared humour) that promoted feelings of gratitude.

\section{Implications}

This study supported previous research findings that operating in unfamiliar cultural contexts is generally more stressful and can cause psychological adjustment issues (e.g., Berno \& Ward, 2005). Data also reinforced findings that tour guiding can be stressful, adventure guiding requires high levels of emotional labour, and that guiding can be associated with negative well-being outcomes, such as feelings of tension, anger, frustration, conflicting emotions, and potentially physical illness (e.g., Ap \& Wong, 2001; Furnham, 1984; Pearce \& Stringer, 1991; Sharpe, 2005). The authors found that emotional labour may occur in employer-guide relations, in addition to guide-client interactions, and that this may contribute to dissatisfaction, burnout, and turnover. In addition to these sources of stress, the adventure tourism guide in this study experienced similar stressors to those documented with hospitality staff (e.g., Law et al., 1995; Ross, 1993), such as stress stemming from management practices and interpersonal interactions (e.g., poor communication from management, lack of incentives, insufficient staff).

This investigation has a range of practical and theoretical implications. Foremost, it provides both adventure tourism guides and operators with insights into the potential difficulties and rewards encountered when guiding, particularly in intercultural contexts. Guides can expect to experientially learn about diverse cultural perspectives of adventure, risk, customer service, and the role of an adventure guide. They can also expect to expand their awareness of different guiding and risk management techniques, equipment, operational procedures, regulatory requirements, and outdoor environments. This is important knowledge that can enhance adventure guides' skill sets and can be transferred to their home country or other international contexts. Conversely, guides may experience high levels of tension stress (mismatching of experienced and preferred feelings) that can result the negative outcomes discussed above. Therefore, it is important that both guides and employers recognise potential stressors, such as those identified in this study, and adopt proactive strategies to prevent guide stress from leading to decreased safety standards, tourist satisfaction, or guide health.

This study suggested that local knowledge, awareness of intercultural differences, and language proficiency may help promote successful adventure tourism guiding experiences in foreign countries, in addition to vital technical skills. The ability to quickly adapt not only to new cultural environments and norms, but also to new outdoor environments, equipment, and regulatory standards are important adventure guiding skills. If a guide lacks sufficient psychological skills to effectively reduce tension stress or reverse current motivational states (e.g., thereby viewing novel challenges as exciting rather than anxiety-producing), negative well-being outcomes may develop. It is recommended that, alongside technical skills, guides develop a robust psychological skill set that enables them to regulate emotions and cope with a range of motivational states, stressors, and negative emotions. This could be facilitated by developing mentoring relationships with experienced adventure guides, or by employers who can help support the development of these mental skills through training programs or one-on-one mentoring for new guides. Traditional mental skill training approaches from sport settings could also be adopted to address some of these issues (see Tenenbaum \& Eklund, 2007 for review). Employers and guides could benefit from awareness of how to use these skills for motivational and performance purposes, and to cope with emotions resulting from interpersonal transactions.

Developing social support networks can also help new or foreign guides navigate intercultural environments and cope with novel stressors. Given that people with greater social support networks have better mental and physical health, and that social support has been shown to moderate the impacts of stressful travel and work experiences on mental health outcomes (e.g., Chen, Siu, Lu, Cooper, \& Phillips, 2009; Ward, 1996, 2001), social support can be an important stress reduction strategy for adventure guides. Guides themselves should be proactive in developing supportive relationships prior to (via internet networking sites and word of mouth contacts) and upon arrival in a new location. These networks could be facilitated by employers or local tourism authorities by providing social networking opportunities to seasonal guides.

The psychological benefits of intercultural training have also been identified (see Brislin \& Yoshida, 1994 for review) and these principles could be adapted for foreign adventure tourism guides and their employers to facilitate their unique intercultural contexts. Intercultural training programs have been shown to promote realistic goals and achievement expectations in other cultures, decrease stress and stereotyping, and increase: cultural awareness (of one's own culture and others); the ability to solve problems incorporating cultural differences; confidence in dealing with cultural differences; enjoyment during intercultural interactions; and performance in heterogeneous work groups (e.g., Brislin \& Yoshida, 1994). Notwithstanding these proposed benefits, many of these programs lack an established theoretical and empirical basis in psychology (Berno \& Ward, 2005) and may prove difficult to actually implement, particularly for smaller adventure tourism operators. Thus, the results of the current study and future investigations of tourism grounded in psychological theory, could inform the development of practical, small-scale intercultural training programs, mental skills training programs, and management strategies for adventure tourism contexts. Furthermore, the psychological framework presented herein could be used to empirically evaluate program effectiveness in future research.

\section{Limitations}

The purpose of this study was to provide critical analysis and interpretation of an 'insider' account of stress and emotions experienced in adventure guiding. Although unique and nuanced insights were gained via the autoethnographical methodology, there were limitations to this approach. The data was situated and constructed within the lead author's previous personal experiences and cultural values. Her background in adventure guiding, tourism, and psychological theories may have sensitised data analysis to issues surrounding risk management, guiding service quality, and reversal theory constructs. While we believe this enhanced the 
depth of analysis in a number of ways, it may have limited alternative interpretations of these data. The lead author's position as a western, female guide operating in a foreign language and a culture that endorsed more traditional gender roles may have also influenced these findings. Therefore 'insider' accounts of adventure guiding from non-foreign, non-western, or male guides would complement these findings in the tourism literature. However, given that females are traditionally underrepresented in the adventure literature and that many adventure tourism guides must operate in intercultural settings, this psychological analysis of adventure guiding experiences provides valuable information for researchers and practitioners alike. Moreover, this investigation addressed the lack of longitudinal research on guide experiences, and calls to further integrate established psychological theory and experiential approaches in tourism research (e.g., Berno \& Ward, 2005; Weber, 2008).

\section{Future directions}

Increasing globalisation, the growing demand for adventure tourism, and the seasonal nature of adventure guiding opportunities make understanding the psychosocial dynamics present in adventure tourism guiding contexts, particularly intercultural settings, an essential avenue for future research. For example, researchers should investigate the psychological implications of dual relationships that frequently develop in 'live-in' situations, or isolated communities, where peers and employers may be close friends, surrogate families, and/or superiors and employers. These studies could produce a range of practical implications for the safe and effective management of adventure tourism activities. Intervention research designs may also be particularly useful to evaluate the effectiveness of intercultural or psychological skills training for adventure guides and employers. Reversal theory analyses of adventure experiences should also be examined amongst larger and more diverse samples and across a broader range of activities, nationalities, and genders to address limitations of the current study.

Reversal theory is a framework that offers a coherent account of the psychological mechanisms governing adventure tourism guiding experiences and resulting emotional fluctuations. This framework enhances our understanding of how stress and coping principles relate to adventure guiding experiences by demonstrating the structure and interrelated nature of cognitions, emotions and motivational states. Research that improves our understanding of common motivational state patterns and resulting emotions can provide well-defined management implications for practitioners and aid theoretical developments. Just as contextspecific models of tourists' consumptive emotions were developed from general psychology, the application of reversal theory to understand tourism workers' experiences and employer-guide interactions in particular, may lead to the development and integration of these concepts into tourism theory and discourse.

The psychological mechanisms described in reversal theory may also have the potential to inform developments in consumptive emotion research. Reversal theory explains emotional experiences via paired metamotivational states that allow for the prediction of emotional responses based on current metamotivational states, rather than the 'objective' events or outcome expectations identified in much of the tourism literature. The identification of frequent high intensity, often negative, emotional states in this study contrasted with previous findings of generally positive emotional reports by tourists (e.g., Coghlan \& Pearce, 2009; Richins, 1997). This discrepancy may highlight key contextual differences between the current study findings and dominant tourism models of emotional experiences. While reversal theory and consumptive emotion models share key emotions, findings suggest that current consumptive emotion models may be inappropriate to explain tourism work experiences. Future research should further explore potential areas of convergence and divergence in models of emotional experience amongst tourists and tour guides.

Tourism settings are ideally suited to developing and applying psychological theories and studying issues such as stress and emotional labour. Exploring the multitude of interpersonal interactions and novel environments experienced by tourists, guides, and operators, all of whom could be foreign visitors or members of the host culture, can provide novel insights into the human psyche. This study contributed to critical tourism literature in a number of ways. It addressed research gaps by providing an in-depth, exploratory autoethnographical study of adventure guiding experiences over time from an 'insider' perspective. It also identified and explained key motivational and emotional states experienced during adventure tourism guiding, and potential sources of stress in the relationship between adventure guides and their employers. These findings were then used to make recommendations for practice which could alleviate stressful experiences between employers and guides. Finally, the current study integrated an established psychological framework that has the potential to enrich future tourism research and discourse.

\section{References}

Anderson, L. (2006). Analytic autoethnography. Journal of Contemporary Ethnography, 35, 373-394.

Anderson, L., \& Austin, M. (2012). Auto-ethnography in leisure studies. Leisure Studies, 31(2), 131-146.

Ap, J., \& Wong, K. (2001). Case study on tour guiding: professionalism, issues and problems. Tourism Management, 22, 551-563.

Apter, M. J. (1982). The experience of motivation: The theory of psychological reversals. London: Academic Press.

Apter, M. J. (1989). Reversal theory: Motivation, emotion and personality. London: Routledge.

Apter, M. J. (1992). The dangerous edge: The psychology of excitement. New York: Free Press.

Apter, M. J. (2001). Motivational styles in everyday life: A guide to reversal theory. Washington, D.C: American Psychological Association.

Apter, M. J., \& Batler, R. (1997). Gratuitous risk: a study of parachuting. In S. Svebak, \& M. J. Apter (Eds.), Stress and health: A reversal theory perspective (pp. 119-129). Washington, D.C.: Taylor \& Francis.

Arnould, E., \& Price, L. (1993). River magic: extraordinary experience and the extended service encounter. Journal of Consumer Research, 20, 24-45.

Ateljevic, I., Pritchard, A., \& Morgan, N. (2007). The critical turn in tourism studies: Innovative research methods. Oxford: Elsevier.

Babiker, I. E., Cox, J. L., \& Miller, P. (1980). The measurement of cultural distance and its relationship to medical consultations, symptomatology and examination performance of overseas students at Edinburgh University. Social Psychiatry, 15 109-116.

Bagozzi, R. P., Gopinath, M., \& Nyer, P. U. (1999). The role of emotions in marketing. Journal of the Academy of Marketing Science, 27(2), 184-206.

Barnes, T. J., \& Sheppard, E. (2000). Introduction: the art of economic geography. In E. Sheppard, \& T. J. Barnes (Eds.), A companion to economic geography (pp. 1-8) Oxford: Blackwell.

Beedie, P. (2003). Mountain guiding and adventure tourism: reflections on the choreography of the experience. Leisure Studies, 22, 147-167.

Bellew, E., \& Thatcher, J. (2002). Metamotivational reversals in competitive sport Social Behavior and Personality: An International Journal, 30(6), 613-623.

Berno, T., \& Ward, C. (2005). Innocence abroad: a pocket guide to psychological research on tourism. American Psychologist, 60(6), 593-600. http://dx.doi.org/ 10.1037/0003-066X.60.6.593.

Biddle, S. J. H., Markland, D., Gilbourne, D., Chatzisarantis, N. L. D., \& Sparkes, A. C. (2001). Research methods in sport and exercise psychology: quantitative and qualitative issues. Journal of Sports Sciences, 19, 777-809.

Brislin, R., \& Yoshida, T. (1994). Intercultural communication training: An introduction. Thousand Oaks, CA: Sage.

Brotheridge, C. M., \& Grandey, A. A. (2002). Emotional labor and burnout: comparing two perspectives of "people work". Journal of Vocational Behavior, 60(1), 17-39.

Brotheridge, C. M., \& Lee, R. T. (2003). Development and validation of the emotional labour scale. Journal of Occupational and Organisational Psychology 76(3), 365-379.

Buckley, R. (2012). Rush as a key motivation in skilled adventure tourism: resolving the risk recreation paradox. Tourism Management, 33(4), 961-970. http:// dx.doi.org/10.1016/j.tourman.2011.10.002. 
Bunce, J. (1998). Sustaining the wilderness therapist. In Exploring the boundaries of adventure therapy: International perspectives, proceedings of the international adventure conference (pp. 189-200). Perth, Australia.

Chen, W., Siu, O., Lu, J., Cooper, C., \& Phillips, D. (2009). Work stress and depression: the direct and moderating effects of informal social support and coping. Stress and Health, 25(5), 431-443.

Chirivella, E. C., \& Mayor, M. L. (1994). The sensation of risk and motivational tendencies in sports: an empirical study. Personality and Individual Differences, 16(5), 777-786.

Cogan, N., \& Brown, R. (1999). Metamotivational dominance, states and injuries in risk and safe sports. Personality and Individual Differences, 27(3), 503-518.

Coghlan, A., \& Pearce, P. (2009). Tracking affective components of satisfaction. Tourism and Hospitality Research, 10(1), 42-58.

Constanti, P., \& Gibbs, P. (2005). Emotional labour and surplus value: the case of holiday 'reps'. Service Industries Journal, 25(1), 103-116.

Denzin, N. K. (1997). Interpretive ethnography: Ethnographic practices for the 21st century. Thousand Oaks, CA: Sage.

Denzin, N. K., \& Lincoln, Y. S. (Eds.), (1994). Handbook of qualitative research. Thousand Oaks, CA: Sage.

Denzin, N. K., \& Lincoln, Y. S. (Eds.), (2005). The Sage handbook of qualitative research (3rd ed.). Thousand Oaks, CA: Sage.

Dickson, J. M. (2006). Perceived consequences underlying approach goals and avoidance goals in relation to anxiety. Personality and Individual Differences, 41(8), 1527-1538.

Duncan, M. (2004). Autoethnography: critical appreciation of an emerging art. International Journal of Qualitative Methods, 3(4), Article 3. Retrieved July 6th, 2012, from. http://www.ualberta.ca/ iiqm/backissues/3_4/pdf/duncan.pdf.

Ellis, C., \& Bochner, A. (2000). Autoethnography, personal narrative, reflexivity: researcher as subject. In N. Denzin, \& Y. Lincoln (Eds.), The Sage handbook of qualitative research (pp. 733-768). Thousand Oaks, CA: Sage.

Erickson, R. J., \& Wharton, A. S. (1997). Inauthenticity and depression: assessing the consequences of interactive service work. Work and Occupations, 24(2) $188-214$.

Fine, E. C., \& Speer, J. H. (1985). Tour guide performances as sight sacralisation. Annals of Tourism Research, 12(1), 73-95.

Florenthal, B., \& Shoham, A. (2001). The impact of persuasive information on changes in attitude and behavioural intentions toward risky sports fo arousal-seeking versus arousal-avoiding individuals. Sport Marketing Monthly, $10,83-95$.

Furnham, A. (1984). Tourism and culture shock. Annals of Tourism Research, 11, 41-57.

Garrett, D., \& Hodkinson, P. (1999). Can there be criteria for selecting research criteria? A hermeneutical analysis of an inescapable dilemma. Qualitative Inquiry, 4, 515-539.

Gass, M. A. (1993). Adventure therapy: Therapeutic applications of adventure programming. Dubuque, IA: Kendall/Hunt Publishing Company.

Goossens, C. (2000). Tourism information and pleasure motivation. Annals of Tourism Research, 27(2), 301-321.

Gould, D., Jackson, S., \& Finch, L. (1993). Sources of stress in national champion figure skaters. Journal of Sport E' Exercise Psychology, 15(2), 134-159.

Guerrier, Y., \& Adib, A. (2003). Work at leisure and leisure at work: a study of the emotional labour of tour reps. Human Relations, 56(11), 1399-1417.

Gyimothy, S., \& Mykletun, R. J. (2004). Play in adventure tourism: the case of artic trekking. Annals of Tourism Research, 31(4), 855-878.

Hall, M. (2004). Reflexivity and tourism research. In J. Phillimore, \& L. Goodson (Eds.), Qualitative research in tourism (pp. 137-155). London: Routledge.

Hardy, L., Jones, G., \& Gould, D. (1996). Understanding psychological preparation for sport: Theory and practice of elite performers. New York: John Wiley \& Sons.

Hochschild, A. R. (1983). The managed heart: Commercialization of human feeling. Berkeley, CA: University of California Press.

Holyfield, L., \& Jonas, L. (2003). From river guide to river grunt: identity, emotions and the river guide. Symbolic Interaction, 26(2), 285-306.

Houge Mackenzie, S., Hodge, K., \& Boyes, M. (2011). Expanding the flow model in adventure activities: a reversal theory perspective. Journal of Leisure Research 43(4), 519-544.

Huang, S., Hsu, C., \& Chan, A. (2010). Tour guide performance and touris satisfaction: a study of the package tours in Shanghai. Journal of Hospitality $\mathcal{E}$ Tourism Research, 34, 3-33.

Hudson, J., \& Walker, N. C. (2002). Metamotivational state reversals during matchplay golf: an idiographic approach. Sport Psychologist, 16(2), 200-217.

Izard, C. (1991). The psychology of emotions. New York: Plenum Press.

Johnson, A. R., \& Stewart, D. W. (2005). A re-appraisal of the role of emotion in consumer behavior: traditional and contemporary approaches. In N. K. Malhotra (Ed.), Review of marketing research, Vol. 1 (pp. 3-34). Emerald Group Publishing Limited. http://dx.doi.org/10.1108/S1548-6435(2004)0000001005.

Jonas, L. (1999). Making and facing danger: constructing strong character on the river. Symbolic Interaction, 22(3), 247-267.

Jonas, L. M., Stewart, W. P., \& Larkin, K. W. (2003). Encountering Heidi: audiences for a wilderness adventurer identity. Journal of Contemporary Ethnography, 32 403-431.

Kerr, J. H. (1987). Differences in motivational characteristics of 'professional', 'serious amateur' and 'recreational' sports performers. Perceptual and Motor Skills, 64, 379-382.

Kerr, J. H. (1989). Anxiety, arousal, and sport performance: an application of reversal theory. In D. Hackfort, \& C. D. Spielberger (Eds.), Anxiety in sports: An international perspective (pp. 137-151). New York: Hemisphere.
Kerr, J. H. (1991). Arousal seeking in risk sport participants. Personality and Individual Differences, 12(6), 613-616.

Kerr, J. H. (1994). Understanding soccer hooliganism. Buckingham, England: Open University Press.

Kerr, J. H. (1999). Motivation and emotion in sport: Reversal theory. East Sussex, UK: Psychology Press.

Kerr, J. H. (2001). Sport and exercise. In M. J. Apter (Ed.), Motivational styles in everyday life: A guide to reversal theory (pp. 187-214). Washington D.C: American Psychological Association.

Kerr, J. H. (2007). Sudden withdrawal from skydiving: a case study informed by reversal theory's concept of protective frames. Journal of Applied Sport Psychology, 19(3), 337-351.

Kerr, J. H., \& Apter, M. J. (Eds.), (1991). Adult play: A reversal theory approach. Amsterdam: Swets \& Zeitlinger.

Kerr, J. H., \& Cox, T. (1991). Arousal and individual differences in sport. Personality and Individual Differences, 12(10), 1075-1085.

Kerr, J. H., Fujiyama, H., \& Campano, J. (2002). Emotion and stress in serious and hedonistic leisure sport activities. Journal of Leisure Research, 34(3), 272-289.

Laros, F., \& Steenkamp, J. B. (2005). Emotions in consumer behavior: a hierarchical approach. Journal of Business Research, 58, 1437-1445.

Law, J., Pearce, P., \& Woods, B. (1995). Stress and coping in tourist attraction employees. Tourism Management, 16(4), 277-284.

Lazarus, R. S. (1991). Emotion and adaptation. New York: Oxford University Press.

Legrand, F. D., \& Apter, M. J. (2004). Why do people perform thrilling activities? A study based on reversal theory. Psychological Reports, 94(1), 307-313.

Legrand, F., \& LeScanff, C. (2003). Tension-stress, effort-stress and mood profiling with an elite javelin performer. Psychology of Sport and Exercise, 4(4), 429-436.

Lincoln, Y. S., \& Guba, E. G. (1985). Naturalistic inquiry. Newbury Park, CA: Sage.

Liu, Y., Perrewe, P. L., Hochwarter, W. A., \& Kacmar, C. J. (2004). Dispositional antecedents and consequences of emotional labor at work. Journal of Leadership and Organisational Studies, 10(4), 12-25.

Lv, Q., Shi, X., \& Hui, J. (2012). Emotional labor strategies, emotional exhaustion, and turnover intention: an empirical study of Chinese hotel employees. Journal of Human Resources in Hospitality \& Tourism, 11(2), 87-105.

Mak, A., Wong, K., \& Chang, R. (2011). Critical issues affecting the service quality and professionalism of the tour guides in Hong Kong and Macau. Tourism Management, 32, 1442-1452.

Males, J., Kerr, J., \& Gerkovich, M. M. (1998). Metamotivational states during canoe slalom competition: a qualitative analysis using reversal theory. Journal of Applied Sport Psychology, 10(2), 185-200.

Marchland, G., Russell, K., \& Cross, R. (2009). An empirical examination of outdoor behavioral healthcare field instructor job-related stress and retention. Journal of Experiential Education, 31(3), 359-375.

Martin, R. A., Kuiper, N. A., Olinger, L. J., \& Dobbin, J. (1987). Is stress always bad? Telic versus paratelic dominance as a stress-moderating variable. Journal of Personality and Social Psychology, 53(5), 970-982.

Monat, A., \& Lazarus, R. S. (Eds.), (1991). Stress and coping: An anthology. New York: Columbia University Press.

Morris, J. A., \& Feldman, D. C. (1997). Managing emotions in the workplace. Journal of Managerial Issues, 9(3), 257-275.

Moscardo, G. (2004). East versus West: a useful distinction or misleading myth? Tourism, 52(1), 7-20.

O'Connell, K. A., Cook, M. R., Gerkovich, M. M., Potocky, M., \& Swan, G. E. (1990). Reversal theory and smoking: a state-based approach to ex-smokers' highly tempting situations. Journal of Consulting and Clinical Psychology, 58(4), 489-494.

O'Connell, K. A., Potocky, M., Cook, M. R., \& Gerkovich, M. M. (1991). Metamotivational state interview and coding schedule instruction manual. Kansas City, MO: Midwest Research Institute.

Oliver, R. (1993). Cognitive, affective, and attribute bases of the satisfaction response. Journal of Consumer Research, 20, 418-430.

Pain, M. T., \& Kerr, J. H. (2004). Extreme risk taker who wants to continue taking part in high risk sports after serious injury. British Journal of Sports Medicine, 38, 337-339.

Pearce, P. L. (1981). "Environmental shock": a study of tourists' reactions to two tropical islands. Journal of Applied Social Psychology, 11, 268-280.

Pearce, P. L. (1987). Psychological studies of tourist behaviour and experience. Australian Journal of Psychology, 39(2), 173-182.

Pearce, P. L. (1991). Introduction: the tourism psychology conversation. Australian Psychologist, 26(3), 145-146.

Pearce, P. L. (1996). Recent research in tourist behaviour. Asia Pacific Journal of Tourism Research, 1(1), 7-17.

Pearce, P. L. (2011). Tourist behaviour and the contemporary world. Bristol, UK: Channel View Publications.

Pearce, P. L., \& Stringer, P. F. (1991). Psychology and tourism. Annals of Tourism Research, 18(1), 136-154.

Pomfret, G. (2006). Mountaineering adventure tourists: a conceptual framework for research. Tourism Management, 27(1), 113-123.

Pomfret, G. (2011). Package mountaineer tourists holidaying in the French Alps: an evaluation of key influences encouraging their participation. Tourism Management, 32, 501-510.

Prokop, H. (1970). Psychiatric illness of foreigners vacationing in Innsbruck. Neurochirugie und Psychiatrie, 107, 363-368.

Pugliesi, K. (1999). The consequences of emotional labor: effects on work stress, job satisfaction, and well-being. Motivation and Emotion, 23(2), 125-154. 
Richardson, L., \& St. Pierre, E. A. (2005). Writing: a method of inquiry. In N. K. Denzin, \& Y. S. Lincoln (Eds.), The Sage handbook of qualitative research (3rd ed.) (pp. 959-978). Thousand Oaks, CA: Sage.

Richins, M. L. (1997). Measuring emotions in the consumption experience. Journal of Consumer Research, 24(2), 127-146.

Ross, G. F. (1993). Type, severity and incidence of work stressors among Australian hospitality industry employees. Australian Journal of Leisure and Recreation, 3(4), $5-12$.

Schwandt, T. A. (1996). Farewell to criteriology. Qualitative Inquiry, 2, 58-72.

Sharpe, E. K. (2005). "Going above and beyond": the emotional labor of adventure guides. Journal of Leisure Research, 37, 29-50.

Sibthorp, J., Paisley, K., \& Gookin, J. (2007). Exploring participant development through adventure-based recreation programming: a model from the National Outdoor Leadership School. Leisure Sciences, 29, 1-18.

Smith, J. K., \& Hodkinson, P. (2005). Relativism, criteria, and politics. In N. K. Denzin, \& Y. S. Lincoln (Eds.), The Sage handbook of qualitative research (3rd ed.) (pp. 915-932). Thousand Oaks, CA: Sage.

Snow, D., Morrill, C., \& Anderson, L. (2003). Elaborating analytical ethnography: linking fieldwork and theory. Ethnography, 2, 181-200.

Sparkes, A. C. (2000). Autoethnography and narratives of self: reflections on criteria in action. Sociology of Sport Journal, 17, 21-41.

Spradley, J. P., \& Phillips, M. (1972). Culture and stress: a quantitative analysis. American Anthropologist, 74, 518-529.

Svebak, S., \& Apter, M. J. (1997). Stress \& health: A reversal theory perspective. Washington, D.C.: Taylor \& Francis.

Svebak, S., \& Kerr, J. H. (1989). The role of impulsivity in preference for sports. Personality and Individual Differences, 10, 51-58.

Svebak, S., Nordby, H., \& Ohman, A. (1987). The personality of the cardiac responder: interaction of serious-mindedness and Type A behavior. Biological Psychology, 24, 1-9.

Tenenbaum, G., \& Eklund, R. C. (2007). Handbook of sport psychology (3rd ed.). Hoboken, New Jersey: John Wiley \& Sons.

Thatcher, J., Reeves, S., Dorling, D., \& Palmer, A. (2003). Motivation, stress and cortisol responses in skydiving. Perceptual and Motor Skills, 97, 995-1002.

Trimpop, R. M., Kirkcaldy, B., \& Kerr, J. H. (1996). Comparing personality constructs of risk-taking behavior. Personality and Individual Differences, 26, 237-254.

Van Dijk, P., Smith, L., \& Cooper, B. (2011). Are you for real? An evaluation of the relationship between emotional labour and visitor outcomes. Tourism Management, 32(1), 39-45.

Ward, C. (1996). Acculturation. In D. Landis, \& R. Bhagat (Eds.), Handbook of intercultural training (2nd ed.) (pp. 124-147). Thousand Oaks, CA: Sage.

Ward, C. (2001). The ABCs of acculturation. In D. Matsumoto (Ed.), Handbook of culture and psychology (pp. 411-445). New York: Oxford University Press.

Weber, K. (2008). Outdoor adventure tourism: a review of research approaches. In M. Weed (Ed.), Sport \& tourism: A reader (pp. 57-70). New York: Routledge.

Witz, A., Warhurst, C., \& Nickson, D. (2003). The labour of aesthetics and the aesthetics of organisation. Organisation, 10(1), 33-54.

Wong, J., \& Wang, C. (2009). Emotional labor of the tour leaders: an exploratory study. Tourism Management, 30, 249-259.
Wyer, R. S., \& Collins, J. E. (1992). A theory of humor elicitation. Psychological Review 99, 663-688.

Xola Consulting. (2010, August). Adventure tourism market report. Retrieved from Xola Consulting Industry research reports online. http://www.xolaconsulting. com/Adventure-Market-2010.pdf.

Zapf, D. (2002). Emotion work and psychological well-being: a review of the literature and some conceptual considerations. Human Resource Management Review, 12(2), 237-268.

Zapf, D., \& Holz, M. (2006). On the positive and negative effects of emotion work in organisations. European Journal of Work and Organisational Psychology, 15(1), $1-28$.

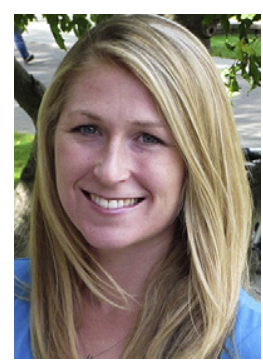

Susan Houge Mackenzie, $\mathrm{PhD}$, is an assistant professor at the University of Idaho. She studies psychological aspects of adventure across tourism, recreational, and educational settings within positive psychology frameworks. Her research investigates how engaging in outdoor adventure contributes to well-being. She also develops theories and methodologies that support this area of research. These research interests are grounded in her long-term experiences as a whitewater guide and competitive sportsperson across four continents. Susan's research has been applied across a range of domains, such as developing mental skills workshops, educational practices, risk management guidelines, and consulting with government agencies and industry operators in New Zealand, South America, and the USA.

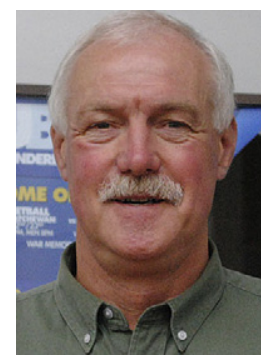

John $\mathbf{H}$. Kerr, PhD, is an adjunct professor of sport \& exercise psychology at the University of British Columbia. Previously, he held university positions in the UK Netherlands, and Japan. His research interests include the influence of motivation, emotion, and arousal on performance; psychological benefits of participation in physical activities; team process; performance of elite winning and losing teams; and aggression/violence in sport. He has published widely in psychology, sport, and exercise journals and is author, co-author, or editor of 10 psychology books, including Rethinking aggression and violence in sport (2005); Counselling athletes: applying reversa theory (2001); Motivation and emotion in sport (1997): Understanding soccer hooliganism (1994). 